\title{
Life cycle assessment of Chinese radial passenger vehicle tire
}

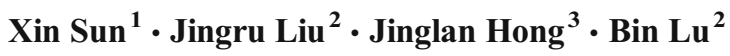

Received: 6 September 2015 / Accepted: 26 May 2016/Published online: 1 June 2016

(C) Springer-Verlag Berlin Heidelberg 2016

\begin{abstract}
Purpose We evaluated and quantified the environmental impact of a radial tire product for passenger vehicles throughout the product's life cycle to identify key stages that contribute to the overall environmental burden and to find ways to reduce these burdens effectively. The study covers all relevant life cycle stages, from the acquisition of raw materials to the production, use, and end of life.

Methods Data collected onsite in 2014 by one of the largest Chinese tire companies were used in the assessment. The evaluation is presented in terms of individual impact category according to the CML model. Five impact categories (i.e., global warming potential (GWP), acidification potential (AP), photochemical oxidant creation potential (POCP), eutrophication potential (EP), and human toxicity potential (HTP)) were considered. The research was conducted in accordance with the ISO 14040/14044 standards.

Results and discussion Fuel (gasoline) consumption represents an important contribution to most impact categories, including the GWP, AP, POCP, and EP, during the use stage. The largest contributor to the HTP category is raw material
\end{abstract}

Responsible editor: Zuoren Nie

Jingru Liu

liujingru@ rcees.ac.cn

1 China Automotive Technology and Research Center, Tianjin 300300, China

2 State Key Laboratory of Urban and Regional Ecology, Research Center for Eco-Environmental Sciences, Chinese Academy of Sciences, Beijing 100085, China

3 Shandong University School of Environmental Science and Engineering, No. 27 Shanda Nan Road, Jinan 250100, China acquisition, mainly because of the impact of the production of organic chemicals. In the end-of-life stage, assuming that $100 \%$ of used tires are collected and recycled to produce reclaimed rubber, the GWP, EP, and HTP contributions are negative, whereas those to the AP and POCP are positive. During the raw material acquisition stage, natural rubber, synthetic rubber, carbon black, and organic chemicals represent the largest contribution to the environmental impact categories. During the production stage, the compound blending process is the largest contributor to the $\mathrm{AP}$ and POCP, whereas vulcanizing and testing contribute most to the GWP, EP, and HTP.

Conclusions Vehicle fuel consumption and its proportion consumed by the tires during the use stage are key factors that contribute to environmental impact during tire life. Further investigations should be conducted to decrease the impact of these factors and improve the environmental performance of tire products.

Keywords Life cycle assessment - Life cycle perspective · Passenger vehicle $\cdot$ Radial tire product $\cdot$ Use-stage fuel consumption

\section{Introduction}

China is the largest producer and seller of motor vehicles worldwide, and this fact has driven tire production and sales in the country. According to data from the China Rubber Industry Association, 562 million tires were produced in China in 2014. Radial tires accounted for $90.92 \%$ of the total (Deng 2015). Among radial tires, the market for radial tires for passenger vehicles has grown rapidly, with 399 million produced in 2014, an increase of $8.1 \%$ from the previous year. In addition, in 2014, the export volume of car tires from China 
was $1.88 \mathrm{Mt}$, which accounted for $33.27 \%$ of the total volume of exported tires (Deng 2015).

Simultaneously, the volume of discarded tires in China has been increasing rapidly; 315 million tires $(\sim 12.35$ million tons) were introduced to the waste stream in 2014. By 2020, it is estimated that the volume of waste tires in China will be $\sim 20$ million tons per year (Cao 2015). It is becoming an urgent environmental and social need to dispose of these waste tires in a timely and safe manner ( $\mathrm{Li}$ and $\mathrm{Xu} 2010$ ).

In recent years, the government and the automotive industry have become increasingly interested in the environmental impact of tire products throughout the tire life cycle because of the significant amounts of resources consumed and pollutants emitted throughout this life cycle.

Life cycle assessment (LCA) has been proposed as a means of compiling and evaluating the inputs, outputs, and potential environmental impact of a product system throughout its life cycle (ISO 2006). Several LCA studies have been conducted on tire products. For example, Kořinek et al. (2012) evaluated the life cycle environmental impact of tire products and compared different waste treatment methods. Feraldi et al. (2013) conducted a comparative LCA of the following two kinds of waste tire treatments: material recycling and tirederived fuel combustion. Li (2013) researched the full life cycle processes of tire production and resource recycling. $\mathrm{Li}$ et al. (2014) assessed the environmental impact of ground rubber produced from scrap tires to provide technical advice for cleaner production. $\mathrm{Li}$ and $\mathrm{Xu}$ (2010) assessed the environmental impact of four kinds of waste tire use methods in China. Xu (2010) identified six types of environmental impacts throughout the life cycle of a radial tire product, considering the raw material acquisition, production, and end-of-life stages but neglecting the use stage.

However, most of these studies focused on the end-of-life disposal of tire products, and few included the entire life cycle from the acquisition of raw materials to the end-of-life stage. Moreover, most LCA studies use foreign life cycle inventory (LCI) databases or secondary LCI databases and literature publications as data sources and therefore cannot represent the life cycle impact of a tire product from a current Chinese passenger vehicle. To address the abovementioned issues, we chose a single radial tire product for passenger vehicles to conduct a cradle-to-grave LCA, and primary on-site investigation data and the Chinese LCI background database were used in the analysis.

\section{Goal and scope definition}

\subsection{Goal and scope}

The objective of this study was to assess environmental impacts, analyze major environmental issues, identify key contributory elements, and seek improvement opportunities throughout the life cycle of a Chinese radial tire product for passenger vehicles.

The functional unit selected for this research was " 60 , $000 \mathrm{~km}$ driven using a radial passenger vehicle tire." The reference flow is "a radial passenger vehicle tire product for use over distances greater than $60,000 \mathrm{~km}$, which weighs $9.497 \mathrm{~kg}$." The technical information regarding the investigated tire product is shown in Table 1.

\subsection{System boundaries}

The entire life cycle of the tire product was considered in this LCA to estimate environmental emissions. The system boundaries are shown in Fig. 1. The four stages investigated were the acquisition of raw materials, production, use, and end of life.

The life cycle processes of the transportation from raw materials to the tire production site and the transportation from tire production site to the recycling and waste treatment plant were investigated. For each life cycle process, the raw materials, energy consumption, road transport requirements, and direct emissions were considered.

However, the impacts of the internal transport of products and semi-finished products during the production stage were not calculated because the relevant data are difficult to collect and the relative contribution is small. The tire product distribution stage was also not considered because a suitable model of the transport and delivery to final users is difficult to confirm, and this stage also has little impact on the results. The manufacturing of capital equipment such as on-site structures, machinery, equipment, and other infrastructure were not considered.

\subsection{Methods and database}

This study was conducted in accordance with the principles of the ISO 14040 series of standards for LCA (ISO 2006). The SimaPro 8 software suite was used as a support tool to establish the LCA model and perform the assessment.

The RCEES 2012 and Ecoinvent 3 databases were used. The former is a local Chinese life cycle inventory database developed by the Research Center for Eco-Environmental Sciences of the Chinese Academy of Sciences based on SimaPro software. It includes more than 1000 units and
Table 1 Technical information of the investigated tire product

\begin{tabular}{ll}
\hline Size & $205 / 55 \mathrm{R} 16$ \\
\hline Load index & 91 \\
Speed rating & $\mathrm{V}$ \\
Weight (kg) & 9.497 \\
Applicable model & Passenger vehicle \\
\hline
\end{tabular}




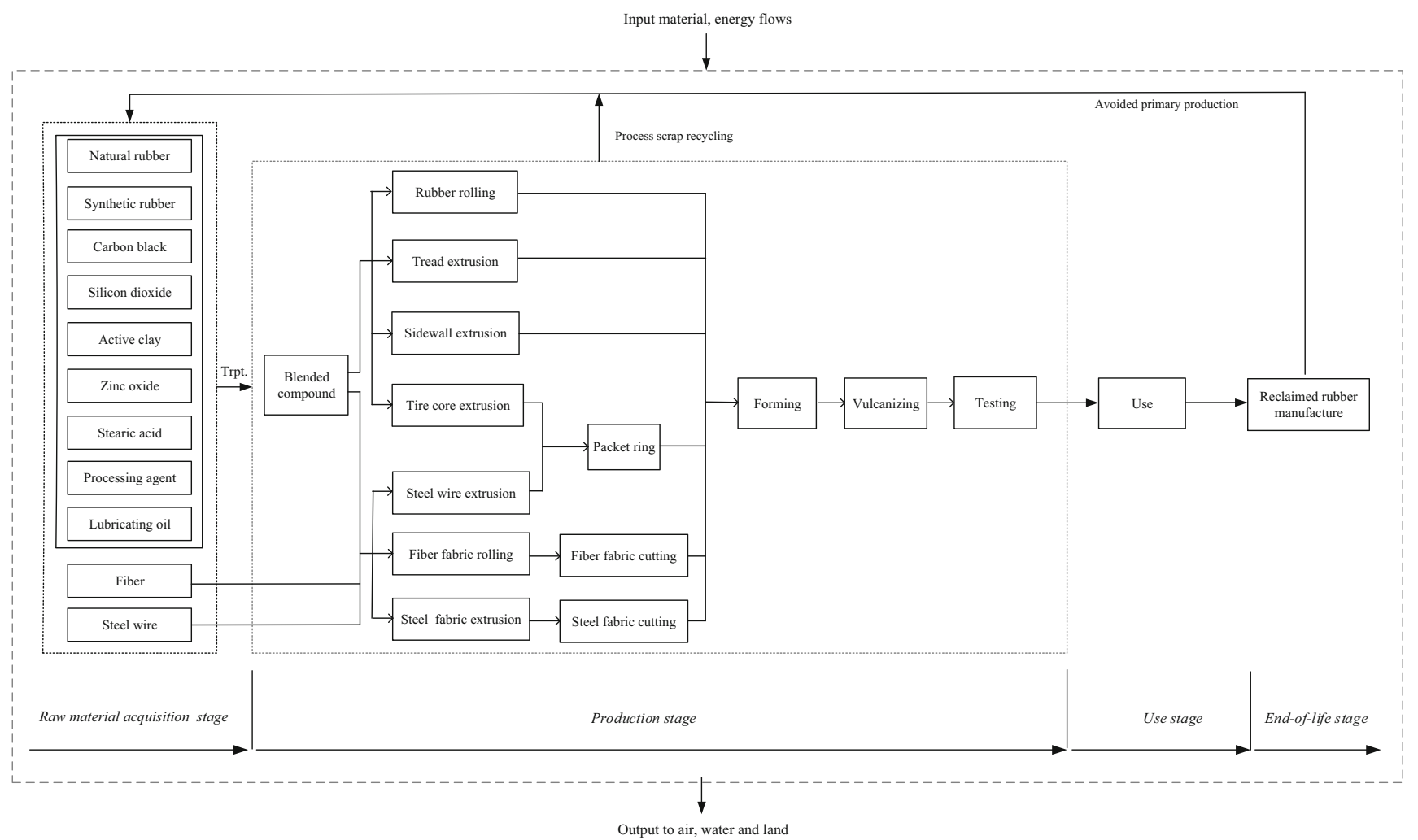

Fig. 1 Tire product life cycle system boundaries

processes, such as transportation and waste treatment as well as metals, minerals, plastics, water, chemicals, fuels, and energy production (Liu et al. 2016; Sun et al. 2014; Yang et al. 2015).

\section{Life cycle inventory analysis}

\subsection{Raw material acquisition stage}

The data on the raw materials used in the investigated tire product were sourced from on-site investigations of one of the largest Chinese tire companies. The data were collected in 2014 during the manufacture of the target tire product. Natural rubber, synthetic rubber, carbon black, silicon dioxide, steel wire, polyester fiber, and nylon 6-6 are the main materials used in the raw material acquisition stage. Background data on all main materials were acquired from RCEES 2012. Other materials, such as active clay, zinc oxide, stearic acid, processing agent, and lubricating oil, were also considered. Life cycle background data on these other materials were obtained from the global average LCI data of Ecoinvent 3.0.

Data on the input of raw materials and the output of solid wastes for the target tire product were measured using the mass allocation method (by allocating the total tire products input/output of the passenger vehicle line to the target tire product). According to an on-site survey, all wastes are recycled $100 \%$ to avoid primary raw material production. The finished tire product has a mass of $9.497 \mathrm{~kg}$. Table 2 shows the specific masses.

\subsection{Production stage}

As shown in Fig. 1, the production stage is quite complex and includes the processes of compound blending, rolling, extrusion, packet ring production, cutting and forming, vulcanizing, and testing. We combined closely related processes to avoid allocation. The following four main production processes were identified: compound blending, rolling and extrusion, cutting and forming, and vulcanizing and testing. Data on the energy consumption and pollutant emissions associated with the tire product were sourced from an on-site investigation of one of the largest Chinese tire companies.

The energy consumption (including hybrid electricity, water, and steam) and pollutant emissions associated with the target tire product were measured using the mass allocation method. Separate from the compound blending process, the three other main processes (cutting and forming, rolling and extrusion, and vulcanizing and testing) result in some simultaneous energy consumption, which is measured by a single monitoring instrument for electricity, water, and steam; thus, this consumption should be calculated collectively to avoid allocation. 
Table 2 LCI of the raw material acquisition and production stages for the target tire product

\begin{tabular}{|c|c|c|c|c|c|c|c|c|}
\hline Category & Subcategory & Unit & $\begin{array}{l}\text { Compound } \\
\text { blending }\end{array}$ & $\begin{array}{l}\text { Rolling and } \\
\text { extrusion }\end{array}$ & $\begin{array}{l}\text { Cutting and } \\
\text { forming }\end{array}$ & $\begin{array}{l}\text { Vulcanizing and } \\
\text { testing }\end{array}$ & $\begin{array}{l}\text { Other three } \\
\text { processes }\end{array}$ & Total \\
\hline \multirow{8}{*}{ Materials } & Natural rubber & $\mathrm{kg}$ & 1.859 & 0.000 & 0.000 & 0.000 & 0.000 & 1.859 \\
\hline & Synthetic rubber & $\mathrm{kg}$ & 2.471 & 0.000 & 0.000 & 0.000 & 0.000 & 2.471 \\
\hline & Carbon black & $\mathrm{kg}$ & 2.515 & 0.000 & 0.000 & 0.000 & 0.000 & 2.515 \\
\hline & Silicon dioxide & $\mathrm{kg}$ & 0.077 & 0.000 & 0.000 & 0.000 & 0.000 & 0.077 \\
\hline & Other materials & $\mathrm{kg}$ & 1.332 & 0.000 & 0.000 & 0.000 & 0.000 & 1.332 \\
\hline & Steel wire & $\mathrm{kg}$ & 0.000 & 1.048 & 0.000 & 0.000 & 0.000 & 1.048 \\
\hline & Nylon 6-6 & $\mathrm{kg}$ & 0.000 & 0.083 & 0.000 & 0.000 & 0.000 & 0.083 \\
\hline & Polyester fiber & $\mathrm{kg}$ & 0.000 & 0.309 & 0.000 & 0.000 & 0.000 & 0.309 \\
\hline \multirow{3}{*}{$\begin{array}{l}\text { Energy and } \\
\text { resource }\end{array}$} & Electricity & MJ & 14.440 & 4.570 & 1.700 & 3.010 & 11.130 & 34.850 \\
\hline & Water & $\mathrm{kg}$ & 6.960 & 0.000 & 0.000 & 0.000 & 16.560 & 23.520 \\
\hline & Steam & $\mathrm{kg}$ & 0.760 & 0.200 & 0.390 & 15.890 & 0.000 & 17.240 \\
\hline \multirow{2}{*}{$\begin{array}{l}\text { Emissions to } \\
\quad \text { air }\end{array}$} & Particle matter (PM) & $\mathrm{g}$ & - & - & - & - & - & 243.510 \\
\hline & $\begin{array}{l}\text { Volatile organic } \\
\text { compounds (VOCs) }\end{array}$ & $\mathrm{g}$ & - & - & - & - & - & 0.005 \\
\hline \multirow[t]{3}{*}{$\begin{array}{l}\text { Emissions to } \\
\text { water }\end{array}$} & $\begin{array}{l}\text { Chemical oxygen demand } \\
\text { (COD) }\end{array}$ & $\mathrm{g}$ & - & - & - & - & - & 1.730 \\
\hline & $\mathrm{NH}_{4}^{+}-\mathrm{N}$ & $\mathrm{g}$ & - & - & - & - & - & 0.190 \\
\hline & Suspended solid (SS) & $\mathrm{g}$ & - & - & - & - & - & 0.690 \\
\hline \multirow[t]{6}{*}{ Solid wastes } & Waste wire cord fabric & $\mathrm{kg}$ & 0.000 & 0.002 & 0.015 & 0.001 & 0.000 & 0.018 \\
\hline & Waste fiber fabric & $\mathrm{kg}$ & 0.000 & 0.001 & 0.020 & 0.001 & 0.000 & 0.022 \\
\hline & Waste cord thread & $\mathrm{kg}$ & 0.000 & 0.001 & 0.000 & 0.000 & 0.000 & 0.001 \\
\hline & Waste rubber & $\mathrm{kg}$ & 0.001 & 0.001 & 0.000 & 0.000 & 0.000 & 0.002 \\
\hline & Waste steel wire & $\mathrm{kg}$ & 0.000 & 0.001 & 0.003 & 0.000 & 0.000 & 0.004 \\
\hline & Waste tire & $\mathrm{kg}$ & 0.000 & 0.000 & 0.000 & 0.073 & 0.000 & 0.073 \\
\hline
\end{tabular}

The specific data on energy consumption and pollutant emission during the production stage are shown in Table 2 . The life cycle background data for hybrid electricity and water were obtained from the RCEES 2012 database (Liu et al. 2016; Sun et al. 2014; Yang et al. 2015), and the life cycle background data for steam were obtained from the global average LCI data of Ecoinvent 3. In total, $34.850 \mathrm{MJ}$ of electricity, $23.520 \mathrm{~kg}$ of water, and $17.240 \mathrm{~kg}$ of steam are consumed during the production stage for one unit of tire product.

The main pollutants include particulate matter and volatile organic compounds emitted into the air and the generation of suspended solids, $\mathrm{NH}_{4}{ }^{+}-\mathrm{N}$, and chemical oxygen demand in water. All data were measured, monitored, and reported in accordance with the national environmental laws.

\subsection{Use stage}

During the use stage, fuel is expended to counteract the rolling resistance of the tires. Fuel consumption during driving was allocated to each of the tires. We used the fuel consumption value provided by the Ministry of Industry and Information Technology of the People's Republic of China (MIIT 2015), which states that the average fuel consumption of Chinese passenger vehicles in 2014 was $7.22 \mathrm{~L} / 100 \mathrm{~km}$. According to a survey of the Chinese car industry, the empirical proportion of a vehicle's fuel consumption that is attributable to the four tires is $20-25 \%$ of the total fuel consumed by the vehicle (Liu et al. 2011; Qian 2010; Yang 2009); for this study, we chose to use a value of $22 \%$. We assumed that the target tire products were used by a gasoline passenger car. The fuel consumption of each tire product throughout its use life of 60 , $000 \mathrm{~km}$ can be calculated based on the fuel consumption of a passenger vehicle $(7.22 \mathrm{~L} / 100 \mathrm{~km})$, the proportion of fuel consumed by the four tires $(22 \%)$, the use life $(60,000 \mathrm{~km})$, and the density of gasoline $(0.73 \mathrm{~kg} / \mathrm{L})$. In this manner, the mass of fuel consumed by each tire product is found to be $173.93 \mathrm{~kg}$.

From the on-site test measurement, the target tire product creates $1.50-\mathrm{kg}$ crumb rubbers because of tire wear abrasion during the lifetime of $60,000 \mathrm{~km}$, which is about $16 \%$ of the tire weight. In other words, each target tire product produces about 25-mg crumb rubber for each kilometer driven. Onekilogram crumb rubber would produce 800 -g particulate matters during the driving ( $\mathrm{Li}$ 2011). Therefore, $1.2 \mathrm{~kg}$ particulate matters will generate through the tire wear abrasion during the lifetime of $60,000 \mathrm{~km}$. 
In our assumption, the gasoline passenger car, which was supposed to use the target tire product, was non-cylinder direct injection engine passenger car. Due to GB 18352.5-2013 "Limits and measurement methods for emissions from lightduty vehicles (China 5)," the measured value of particulate matter could be calculated at zero for non-cylinder direct injection gasoline engine car. Therefore, we conclude no particulate matter emission through the gasoline consumption.

\subsection{End-of-life stage}

Statistics show that in China, $70 \%$ of waste tires can be recycled to produce reclaimed rubber (Jiang 2011). From an on-site survey of a Chinese waste tire recycling company, the inputs and outputs associated with the recycling of reclaimed rubber from $1 \mathrm{t}$ of waste tires are shown in Table 3.

In this study, we assumed that $100 \%$ of used tires are collected and recycled to produce reclaimed rubber and that waste steel wire and waste fiber are recycled to avoid primary raw material production. The reclaimed rubber is reused in place of $50 \%$ of the synthetic rubber used in the production of rubber products. The recycling rates of waste steel wire and waste fiber are 95 and $50 \%$. The remaining components that could not be recycled and reused were treated as municipal solid wastes in accordance with a waste treatment scenario specified in the RCEES 2012 database (Liu et al. 2016; Sun et al. 2014; Yang et al. 2015).

\section{Life cycle impact analysis}

The CML (2001) method developed by the Institute of Environmental Sciences of Leiden University was selected as the base method to be used in this LCA to analyze environmental impacts. We chose five impact categories from this approach that are easily communicated, of general interest, and important with respect to the tire product system. These impact categories are the global warming potential (GWP 100a) in kilograms of $\mathrm{CO}_{2}$ equivalent, the acidification potential (AP) in kilograms of $\mathrm{SO}_{2}$ equivalent, the photochemical oxidant creation potential (POCP) in kilograms of $\mathrm{C}_{2} \mathrm{H}_{4}$ equivalent, the eutrophication potential (EP) in kilograms of $\mathrm{PO}_{4}{ }^{3-}$ equivalent, and the human toxicity potential (HTP $100 \mathrm{a})$ in kilograms of 1,4-DCB equivalent.

\section{Results and discussion}

\subsection{Life cycle assessment results}

The results of the LCA for one tire in all selected categories are presented in Table 4.
Table 3 List of inputs and outputs associated with the recycling of reclaimed rubber from $1 \mathrm{t}$ of waste tires

\begin{tabular}{llcl}
\hline Category & Material & Amount & Unit \\
\hline Inputs & Waste tire & 1.00 & $\mathrm{t}$ \\
& Electricity & 770.50 & $\mathrm{kWh}$ \\
& Water & 7.10 & $\mathrm{t}$ \\
& Diesel & 0.01 & $\mathrm{t}$ \\
Outputs & Reclaimed rubber & 0.67 & $\mathrm{t}$ \\
& Waste steel wire & 0.07 & $\mathrm{t}$ \\
& Waste fiber & 0.01 & $\mathrm{t}$ \\
& $\mathrm{SO}_{2}$ & 0.72 & $\mathrm{~kg}$ \\
& $\mathrm{NO}_{\mathrm{x}}$ & 0.38 & $\mathrm{~kg}$ \\
& $\mathrm{H}_{2} \mathrm{~S}$ & 0.18 & $\mathrm{~kg}$ \\
& Smoke dust & 0.16 & $\mathrm{~kg}$ \\
& Powder dust & 0.19 & $\mathrm{~kg}$ \\
& Non-methane hydrocarbon & 0.76 & $\mathrm{~kg}$ \\
\hline
\end{tabular}

\subsubsection{Global warming potential}

The largest proportion of the GWP burden throughout the life cycle of one tire is related to the use stage $(94.57 \%)$, with the main contributor being fuel consumption. The raw material acquisition $(4.31 \%)$ and tire production $(1.72 \%)$ stages contribute only a small portion of the total. During the end-of-life stage, the recycling of used materials reduces the total GWP by $0.60 \%$.

As shown in Fig. 2, of the various greenhouse gases, $\mathrm{CO}_{2}$ emissions contribute the most to global warming $(99.43 \%)$. The other substances collectively contribute less than $1 \%$ of the total and include predominantly $\mathrm{CH}_{4}(0.38 \%), \mathrm{CO}$ $(0.18 \%)$, and $\mathrm{N}_{2} \mathrm{O}(0.01 \%)$.

\subsubsection{Acidification potential}

During the life cycle of the tire product, the use stage contributes the largest share of the AP $(87.30 \%)$. The contributions from the raw material acquisition $(6.82 \%)$ and production $(5.30 \%)$ stages are similar. The end-of-life stage contributes the least $(0.58 \%)$.

The largest of the life cycle AP burdens is $\mathrm{NO}_{\mathrm{x}}(71.60 \%)$. $\mathrm{SO}_{2}$ is the second greatest contributor, accounting for $28.15 \%$ of the total. The remaining pollutants contribute $0.25 \%$ of the total and include $\mathrm{HCl}(0.18 \%)$ and other pollutants $(0.07 \%)$.

\subsubsection{Photochemical oxidant creation potential}

The use stage accounts for more than half $(63.93 \%)$ of the total POCP of the tire product, followed by the production $(17.61 \%)$ and raw material acquisition $(16.67 \%)$ stages. The end-of-life stage contributes least to the POCP (1.79\%). 
Table 4 LCA results for one tire throughout its life cycle

\begin{tabular}{lccrrr}
\hline Impact category & Raw material acquisition & Production & Use & End of life & Total \\
\hline GWP $\left(\mathrm{kg} \mathrm{CO}_{2} \mathrm{e}\right)$ & 29.786 & 11.849 & 653.328 & -4.119 & 690.844 \\
$\mathrm{AP}\left(\mathrm{kg} \mathrm{SO}_{2} \mathrm{e}\right)$ & 0.143 & 0.111 & 1.826 & 0.012 & 2.091 \\
POCP $\left(\mathrm{kg} \mathrm{C}^{2-\mathrm{H} 4} \mathrm{e}\right)$ & 0.008 & 0.008 & 0.030 & 0.001 & 0.047 \\
EP $\left(\mathrm{kg} \mathrm{PO}_{4}{ }^{3-} \mathrm{e}\right)$ & 0.023 & 0.006 & 0.375 & -0.008 & 0.395 \\
HTP $\left(\mathrm{kg}^{1,4-\mathrm{DCB}} \mathrm{e}\right)$ & 10.081 & 0.743 & 3.495 & -3.391 & 10.927 \\
\hline
\end{tabular}

The POCP is attributed primarily to $\mathrm{SO}_{2}(49.85 \%)$ and $\mathrm{CO}$ $(45.17 \%)$, whereas other pollutants contribute a small proportion $(4.98 \%)$ of the total.

\subsubsection{Eutrophication potential}

The use stage contributes the most $(94.94 \%)$ to the EP. The second greatest contribution to the EP is from the raw material acquisition stage (5.72\%). The production stage contributes $1.48 \%$ of the total. During the end-of-life stage, the recycling of used materials reduces the total EP by $2.14 \%$.

The EP is attributed predominantly to $\mathrm{NO}_{\mathrm{x}}$ emissions $(98.48 \%)$. The remaining pollutants collectively contribute less than $2 \%$, including phosphate $(1.00 \%)$, chemical oxygen demand $(0.28 \%)$, nitrate $(0.14 \%)$, and other pollutants $(0.10 \%)$.

\subsubsection{Human toxicity}

The largest proportion of the HTP burden throughout the life cycle of one tire is related to the raw material acquisition stage $(92.25 \%)$. The second largest contributor to the HTP is the use stage $(31.98 \%)$. The production stage accounts for the smallest contribution to the HTP $(6.80 \%)$. During the end-of- life stage, the recycling of used materials reduces the total EP by $31.03 \%$.

The dominant contributing pollutants in the HTP category are $\mathrm{NO}_{\mathrm{x}}(32.88 \%)$ and benzene $(25.65 \%)$, followed by PAH $(18.62 \%)$ and arsenic $(10.77 \%)$. The remaining pollutants contribute similarly to the total, including nickel $(3.83 \%)$, chromium VI (3.67 \%), and other pollutants $(4.57 \%)$.

\subsection{Interpretation of life cycle results}

\subsubsection{Identification of major issues}

The relative contributions of the different life cycle stages to each impact category for one item of the tire product are shown in Fig. 3. The use stage is the primary contributor to the GWP, AP, POCP, and EP and accounts for $\sim 63-95 \%$ of the total to each impact category, respectively. This is because of the fuel consumption that occurs during the use stage. The other three stages contribute less than $13 \%$ of the total to the GWP, AP, and EP. The raw material acquisition and production stages contribute less than 7 and $6 \%$ of the total, respectively, of each impact category. For the HTP, the largest contributor is the raw material acquisition stage. For the end-oflife stage, the GWP, EP, and HTP contributions are negative

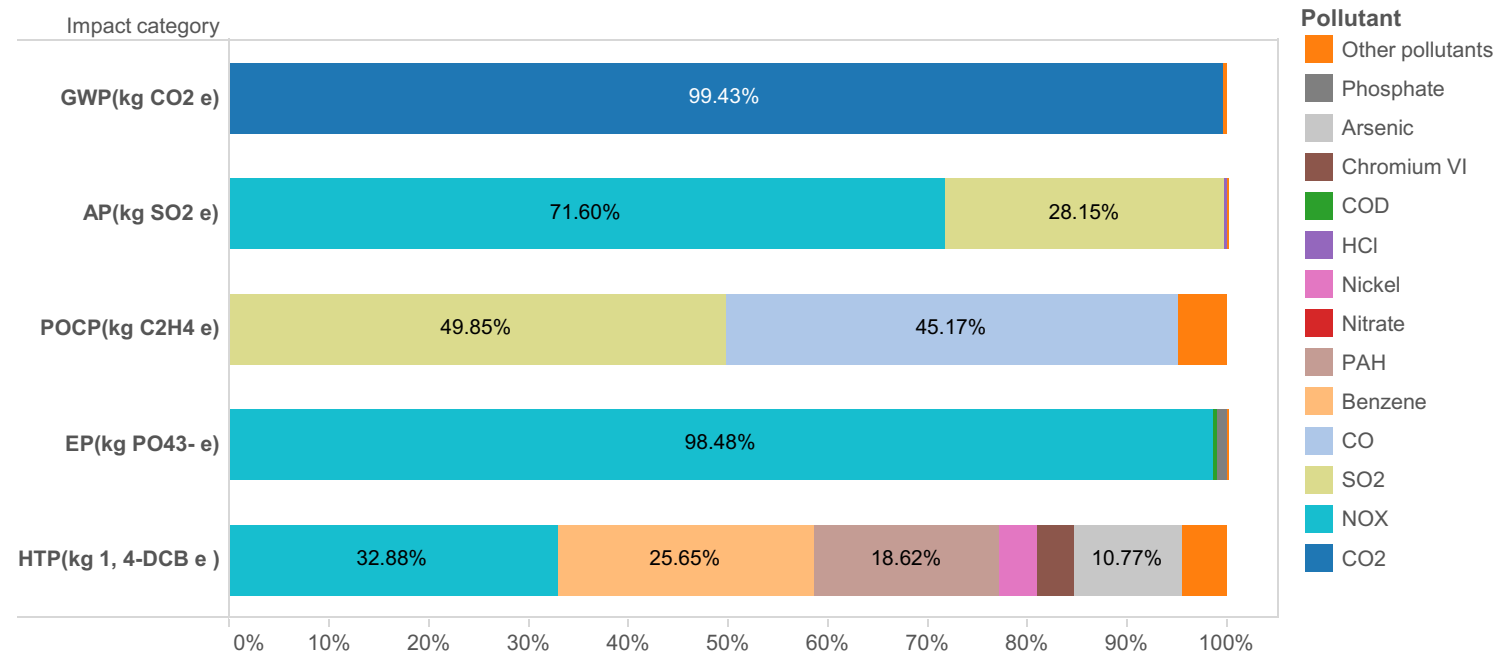

Fig. 2 Contributions of various pollutants to the impacts of one tire 
Fig. 3 Relative contributions of the life cycle stages to each impact category for the investigated tire product

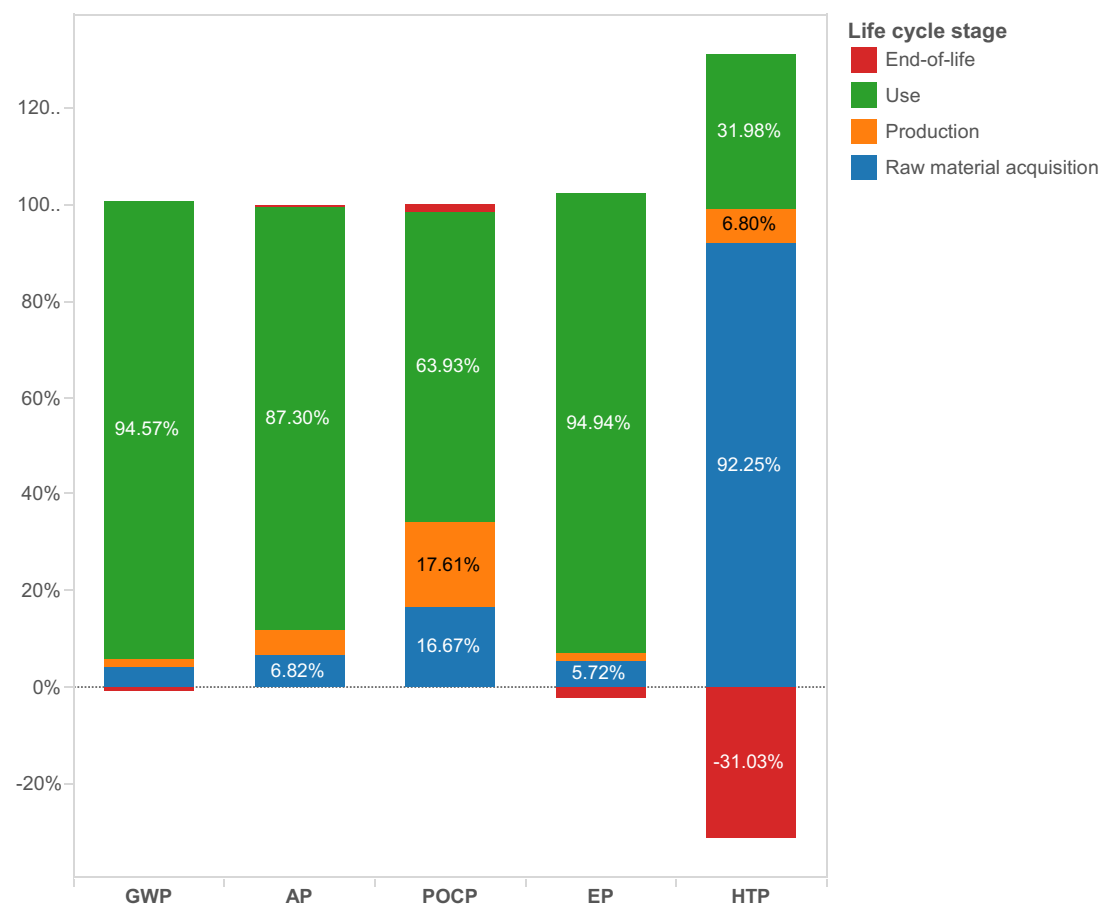

(especially for the HTP) and the AP and POCP contributions are positive.

Figure 4 shows the relative contributions to each impact category of the raw material acquisition stage for the tire product. In the GWP, AP, and EP categories, rubber and carbon black are the predominant contributors. The predominant contributors overall are the rubbers, including both natural and synthetic rubber, which together account for nearly half of the total contribution to each of the three impact categories above. However, for both the HTP and POCP, the largest proportion of the burden in the raw material acquisition stage is related to other materials, with the main contributor being organic chemicals. By contrast, other materials collectively contribute less than $16 \%$ to the other three impact categories. In all five impact categories, carbon black contributes $\sim 11-$ $25 \%$ of the total to each impact category, respectively; steel wire accounts for less than $12 \%$; and fiber contributes less than $8 \%$.

The relative contributions to each impact category in the production stage for the tire product are shown in Fig. 5. The compound blending process is the largest contributor to the AP and POCP, primarily because of its electricity consumption. Vulcanizing and testing contribute the most to the GWP, the EP, and especially the HTP ( $86.30 \%)$; this is ascribed to the significant amounts of steam consumed during vulcanization. In all five impact categories, rolling and extrusion represent contributions of about $10 \%$ to the GWP, AP, POCP, and EP and less than $3 \%$ of the total to the HTP. The "other three processes" contribution, which includes the collective contributions from cutting and forming, rolling and extrusion, and vulcanizing and testing, represents less than $31 \%$ of the total in each impact category; the majority of which can be attributed to the consumption of water and electricity.

In the end-of-life stage, used tires are recycled to produce reclaimed rubber, which is reused in place of synthetic rubber for the production of rubber products. Waste steel wire and waste fiber are recycled to avoid primary raw material production. The relative contributions to each impact category in the end-of-life stage for the tire product are shown in Fig. 6. The impact of the end-of-life stage is negative for the GWP, EP, and HTP. However, the production of reclaimed rubber and waste treatment also exert some environmental impact. As shown in Fig. 6, for the AP and POCP, the environmental benefit from the recycling of waste materials is insufficient to outweigh the environmental impact from reclaimed rubber production and waste treatment. Therefore, AP and POCP impacts exist during the end-of-life stage.

Throughout the life cycle of the tire product, gaseous pollutants, such as $\mathrm{CO}_{2}, \mathrm{NO}_{\mathrm{x}}, \mathrm{SO}_{2}, \mathrm{CO}$, benzene, and $\mathrm{PAH}$, are the main contributors to the environmental impact categories. Figure 7 shows the distribution of these major pollutants throughout the life cycle of the tire product. The use stage contributes the most to emissions of $\mathrm{CO}_{2}, \mathrm{NO}_{\mathrm{x}}(\sim 95 \%)$, total $\mathrm{PM}(80.51 \%)$, and $\mathrm{SO}_{2}$ and $\mathrm{CO}(>64 \%)$ throughout the life cycle. The raw material acquisition stage is the primary contributor (>100\%) to benzene and PAH emissions throughout the life cycle. The production stage contributes more than $10 \%$ of the $\mathrm{PAH}$, total $\mathrm{PM}, \mathrm{SO}_{2}$, and $\mathrm{CO}$ emissions but less than $5 \%$ of the other three pollutants. During the end-of-life stage, the recycling method used to produce reclaimed rubber 


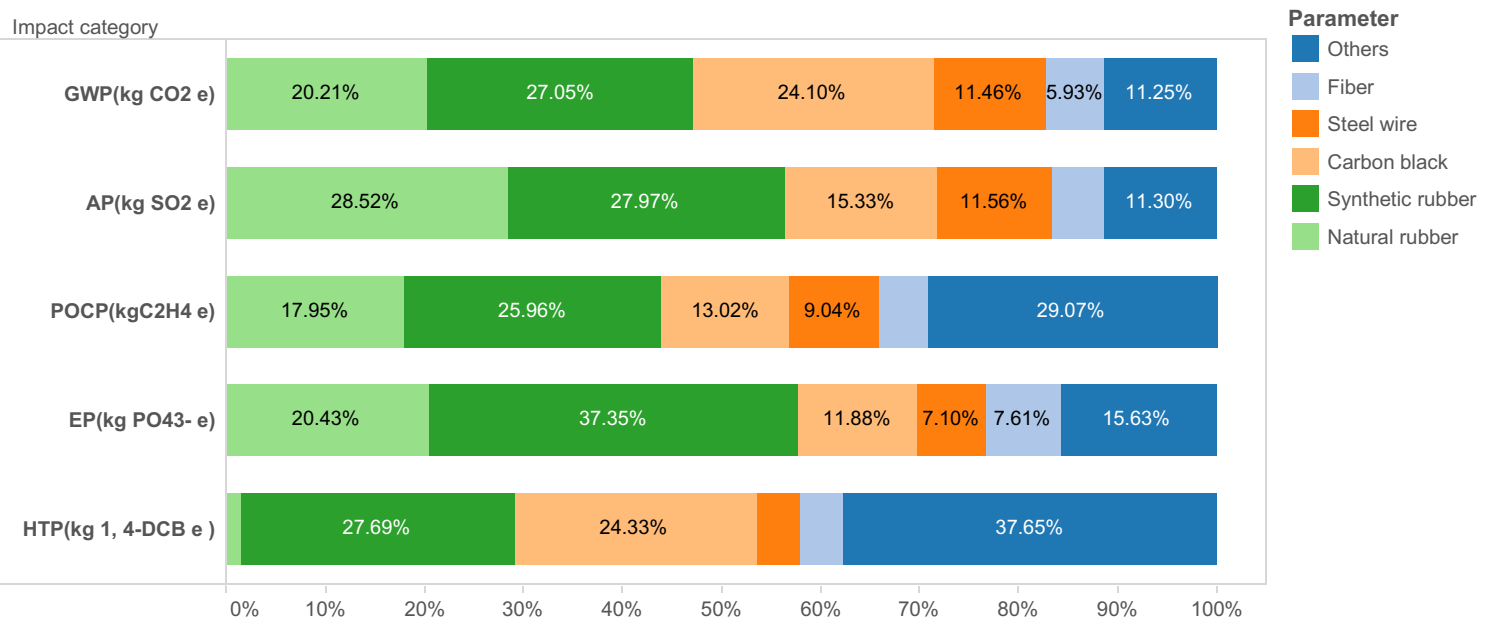

Fig. 4 Relative contributions to each impact category in the raw material acquisition stage for the investigated tire product

serves to reduce a large proportion of the PAH $(50.52 \%)$ and benzene $(15.98 \%)$ emissions but generates a small contribution $(<3 \%)$ to the $\mathrm{SO}_{2}, \mathrm{CO}$, and total PM.

\subsubsection{Sensitivity analysis}

The use stage is the primary contributor to most of the environmental impact categories throughout the life cycle of the tire product, primarily because of the fuel consumed to counteract frictional resistance while driving.

A single-element sensitivity analysis was conducted to examine how fuel consumption influences the environmental impact categories. Two parameters, namely, the vehicle's fuel consumption during the use stage and the proportion of fuel consumed by the tires with respect to the vehicle's total fuel consumption during the use stage, were varied to examine their effects on the contributions to different environmental impact categories.

When the vehicle's fuel consumption during the use stage was varied by $\pm 10 \%$ from its base value $(7.22 \mathrm{~L} / 100 \mathrm{~km})$, the environmental impacts in terms of the GWP, AP, POCP, EP, and HTP changed by $\pm 9.46, \pm 8.73, \pm 6.39, \pm 9.49$, and $\pm 3.20 \%$, respectively.

When the proportion of fuel consumed by the tires with respect to the total during the use stage was varied by $\pm 10 \%$ from its base value ( $22 \%$ ), the environmental impacts in terms of the GWP, AP, POCP, EP, and HTP changed by \pm 9.46 , $\pm 8.73, \pm 6.39, \pm 9.49$, and $\pm 3.20 \%$, respectively.

Therefore, it can be concluded that the vehicle's fuel consumption and the proportion of fuel consumed by the tires during the use stage are key factors that contribute to the environmental impacts of the tire product.

\subsection{Recommendations for improvement}

Based on the research results and their interpretation, the following measures would be useful for improving the environmental impacts observed throughout the tire product life cycle.

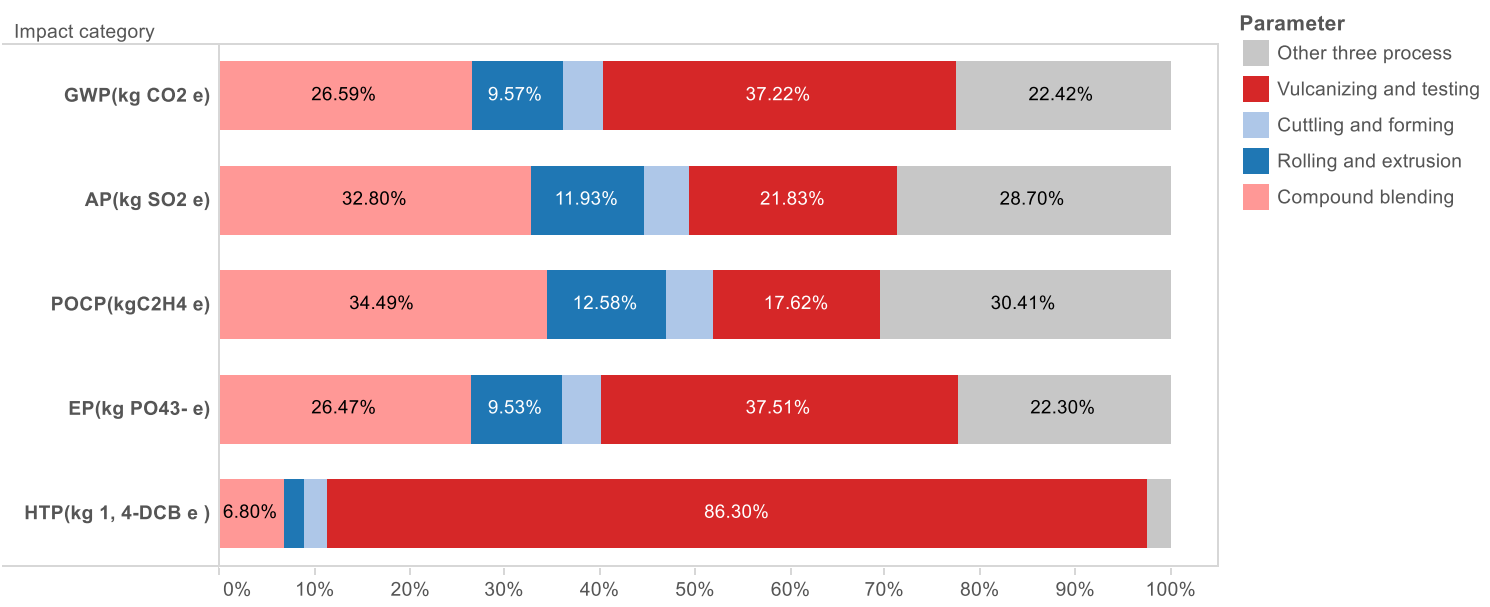

Fig. 5 Relative contributions to each impact category in the production stage for the investigated tire product 


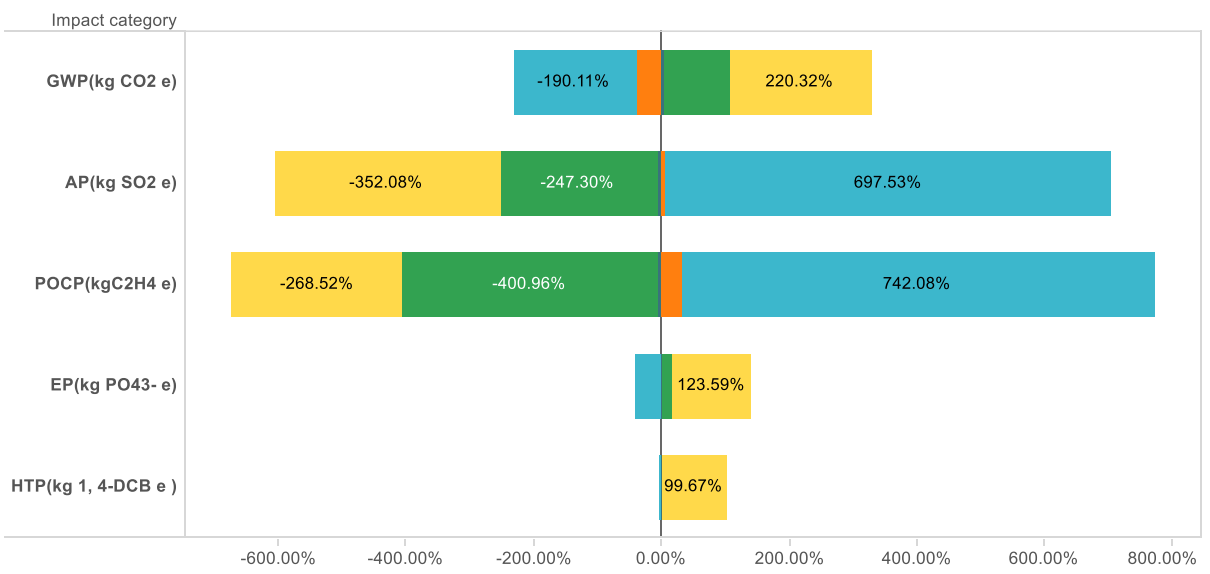

Parameter

Reclamed rubber production

Reuse reclaimed rubber

Recycling steel wire

Recycling Fibre

Waste treatment

Fig. 6 Relative contributions to each impact category in the end-of-life stage for the investigated tire product

First, the use of reclaimed rubber would reduce the consumption of natural and synthetic rubber. Reducing the amounts of organic chemicals used and increasing the use of renewable materials or environmentally friendly materials would increase the environmental benefit during the raw material acquisition stage.

Second, by partially substituting silicon dioxide or silica gel for carbon black as filler, it is possible to reduce the rolling resistance of a tire while maintaining its skid and wear resistances (Krömer et al. 1999; Xiong et al. 2004; Zhang et al. 2014b). This also helps to reduce the fuel consumption of the tire during the use stage and reduces its environmental impact throughout its life cycle. Liu et al. (2011) have reported that the rolling resistance of a silica gel tire, compared with that of an ordinary carbon black tire, can be reduced by a maximum of $15 \%$, thereby leading to a reduction in fuel consumption and greenhouse gas emissions by $\sim 2-3 \%$. In tests performed by Michelin using white carbon black and solution-polymerized butadiene styrene rubber, the rolling resistance of a tire was reduced by $35 \%$ and its fuel consumption was reduced by $\sim 3-5 \%$ (Qian 2010).

Third, to reduce the amounts of electricity, water, and steam consumed during the compound blending and vulcanizing and testing processes in the production stage, on-site management should be strengthened by implementing an intelligent digitalized energy management system. Furthermore, new energy-saving technology could be implemented to improve production efficiency, such as the use of high-pressure steam to shorten the vulcanizing time, the substitution of microcirculation for hot water circulation, and the recovery of waste steam during the vulcanizing process (Hao et al. 2012; Jiang 2013; Zhang et al. 2014a).

\section{Conclusions}

Confidence in measures to improve the environmental performance of products requires a system-wide perspective. LCA

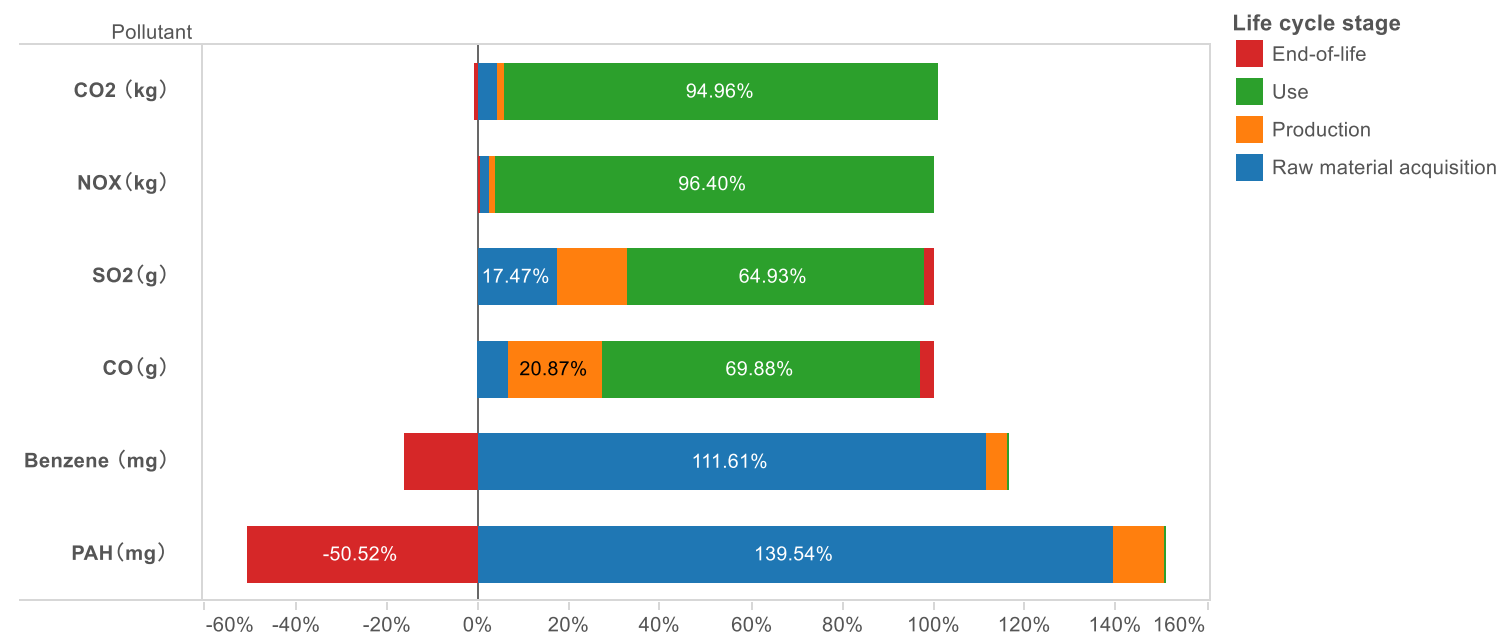

Fig. 7 Distribution of the major pollutants produced throughout the life cycle of the investigated tire product 
and life cycle engineering are valuable tools for achieving this goal.

We present a cradle-to-grave LCA of one Chinese passenger vehicle tire product based on first-hand survey data to assess the product's environmental impacts. Key factors and recommended improvements were identified based on the LCA results.

The use stage was found to contribute the most to the GWP, AP, POCP, and EP impact categories. The vehicle's fuel consumption and the proportion of fuel consumed by the tires during the use stage are key factors in determining the environmental impacts of the tire product. The largest contributor to the HTP category is the raw material acquisition stage, primarily related to the production of organic chemicals. The GWP, EP, and HTP contributions from the end-of-life stage are negative, whereas the AP and POCP contributions from this stage are positive.

During the raw material acquisition stage, natural rubber, synthetic rubber, carbon black, and organic chemicals present the largest contributions to the environmental impact categories. These impacts could be mitigated by replacing some natural and synthetic rubbers with reclaimed rubber and some carbon black with silicon dioxide or silica gel and by reducing the use of organic chemicals. The compound blending and vulcanizing processes exert the greatest environmental impacts during the production stage; therefore, new energysaving technology and an energy management system could be implemented to save energy and reduce emissions during this stage.

Tires are complex products with complex interactions with the environment. Further investigations should be conducted to implement LCA as part of the product development process and improve the environmental performance of tires. Overall, this quantitative LCA study can serve as a benchmark for the environmental performance of Chinese passenger vehicle tire products.

\section{References}

Cao Q (2015) Comprehensive utilization situation in 2014 \& prediction in 2015 of China waste rubber industry. Paper presented at the 2015 China rubber conference, Guangzhou, 7 Apr

Deng Y (2015) Economic operation situation in 2014 \& prediction in 2015 of China rubber industry. Paper presented at the 2015 China rubber conference, Guangzhou, 7 Apr
Feraldi R, Cashman S, Huff M (2013) Comparative LCA of treatment options for US scrap tires: material recycling and tire-derived fuel combustion. Int J Life Cycle Assess 18:613-625

Hao S, Ren Y, Du G (2012) Vulcanization process of energy saving and emission reduction applications of all-steel radial tire. Tire industry, pp 241-244

ISO (2006) ISO 14040: 2006 environmental management—life cycle assessment - principles and framework. International Organization for Standardization, Geneva

Jiang Z (2011) The present situation and the development of comprehensive utilization of waste tyres in China. Adv Rubber Technol 37:3-7

Jiang J (2013) New design thinking and practice effect of energy saving and emission reduction in tyre plant China Rubber, pp 12-16

Kořínek R, Tušil P, Kočí V (2012) Evaluation of the life cycle and comparison of the waste management treatment with tyre by life cycle assessment. J Environ Sci Eng 1:106-119

Krömer S, Kreipe E, Reichenbach D, Stark R (1999) Life cycle assessment of a car tire. Continental AG, Hannover, Germany

Li Z (2011) Research of life cycle assessment and application in the tire industry. Shanghai Jiao Tong University

Li D (2013) Research on the full lifecycle process of tire production and recycling of resources. Guangdong University of Technology

Li X, Xu H (2010) Environmental impact assessment of waste tyre utilization method in China. Environ Pollut Control 11:99-102

Li W, Wang Q, Jin J, Li S (2014) A life cycle assessment case study of ground rubber production from scrap tires. Int J Life Cycle Assess 19:1833-1842

Liu Q, Chen Q, Yang J (2011) The impact of tire rolling resistance on the fuel economy of vehicle automobile parts:77-80 doi:10.3969/j.issn. 1674-1986.2011.08.029

Liu $\mathrm{Z}$ et al. (2016) Targeted opportunities to address the climate-trade dilemma in China. Nature Clim Change6:201-205. http://www. nature.com/nclimate/journal/vaop/ncurrent/abs/nclimate2800. html\#supplementary-information

MIIT (2015) Public announcement of accounting circumstances about China's passenger car corporate average fuel consumption in 2014. Beijing

Qian B (2010) The present situation and the development tendency of energy-saving tyre. Adv Rubber Technol 36:1-6

Sun X, Liu J, Yang D, Lv B (2014) The carbon footprint of household airconditioners and its key influence factors. ACTA Scientiae Circumstantiae 34:1054-1060

Xiong J, Huang Y, Li P, Wang Q (2004) Development and application of new type carbon black in tyre industry. China Synth Rubber Ind 27: 388-390

$\mathrm{Xu} \mathrm{J}$ (2010) Life cycle assessment study of radial tyre product. Northwest University

Yang L (2009) The analysis of tire life cycle economic, energy and carbon emissions. Master, Tongji University

Yang D, Liu J, Yang J, Ding N (2015) Life-cycle assessment of China's multi-crystalline silicon photovoltaic modules considering international trade. J Clean Prod 94:35-45

Zhang M, Chen Q, He J (2014a) Technology energy saving technical reconstruction efficiency analysis of tire production. Tyre Industry, pp 395-399

Zhang S, Zhang H, Liu Y (2014b) Formulation Study of the tread compound for 295/75R22.5 low rolling resistance tire. Rubber Science and Technology, pp 26-29 doi:10.3969/j.issn.2095-5448.2014.11. 008 